\title{
Knowledge Organisations and High-Tech Regional Innovation Systems in Developing Countries: Evidence from Argentina
}

\author{
Carolina Pasciaroni*
}

\begin{abstract}
In the globally and knowledge based economy, the universities and other knowledge organisations are valued for their ability to contribute to the regional innovation processes. This is particularly relevant for the developing countries in South America since their R\&D spending is highly concentrated on the public knowledge infrastructure. However, there are few studies examining the role of knowledge organizations at regional level in Latin America. The proposed study aims to analyse the role played by knowledge organisations in the formation of a high-tech Regional Innovation Systems in Argentina. This country has a number of attractive features relative to the positive evolution of its R\&D spending and the recent implementation of a policy that promotes cooperation between firms and knowledge organisations among high-tech sectors. As evidenced in developed regions, the organisations under study play a key role in the promotion of a high-tech Regional Innovation Systems. However, this prominent role is not based on those local factors identified in the literature, such as organisational and institutional local assets, but on national science and technology policies and individual initiatives conducted by the faculties involved.
\end{abstract}

Keywords: Knowledge Organisations; Links between Universities/I+D Centres and Firms; Regional Innovation Systems; Science and Technology Parks; High-Technology; ICT; Developing Countries

Submitted: March $8^{\text {th }} 2016$ / Approved: Approved: November June $7^{\text {th }} 2016$

\section{Introduction}

In today's knowledge based economy, universities, R\&D centres, and similar knowledge organisations are valued as sources of new knowledge and innovation (Anselin et al, 2000; Bercovitz \& Feldman, 2006; Etzkowitz, 2003; among others). In addition, regions are conceived as privileged sites for the rise of innovation and competitive advantages (see Scott \& Storper, 2003). Thus the empirical evidence shows successful examples of cooperation between firms and research organisations in the well-known regions of Silicon Valley (USA), Boston (USA) and Cambridge (England).

In opposition, studies on National Innovation Systems (NISs) in South America reveal considerably few links between firms and knowledge organisations (Arocena \& Sutz, 2006). In an attempt to complement these studies carried out at national scale, the present manuscript adopts a regional/local perspective for the innovation processes. The Regional Innovation Systems (RISs) theoretical approach is an appropriate framework for analysing the role played by universities, R\&D laboratories, science and technology (S\&T) centres in less development regions. It should be stressed that the RIS approach is not widely disseminated in studies of innovation in Latin America (Llisterri \& Petrobelli, 2011).

The study focuses, particularly, on the factors that determine the capacity of knowledge organisations to promote the creation of hightech RISs in developing countries. Using the case study methodology, the public knowledge infrastructure of the city of Bahía Blanca (Argentina) is discussed, along with its recent initiatives in the field of ICTs: the creation of an S\&T Park on high-complexity electronics.
The selection for the case study is based on several factors. First, in NIS of Argentina, the relation between knowledge organisations and firms is deficient, but stronger in comparison to other countries in South America. In addition, there is a growing interest from the national public sector to promote such links. Second, the organisations under study have a long tradition in knowledge generation and diffusion to the local productive sector.

Following the introduction, this manuscript is structured as follow. Part 2 presents the theoretical framework and a literature review. Part 3 discusses the interactions between knowledge organisations and firms in the NIS of Argentina in comparison to other countries in South America and developed countries. Part 4 describes the case under study and Part 5 analyses the contribution of local knowledge infrastructure to the emergence of a high-tech RIS. Finally, the summary and conclusions are presented.

\section{Literature Review.}

While there is no generalised consensus over the definition (Asheim \& Coenen, 2005) a Regional Innovation System (RIS) can be defined as an interactive knowledge generation and exploitation, connected with other global, regional and national systems (Cooke, 2004 in Asheim \& Coenen, 2005, p. 1174). The background to this approach is divided into two main schools of thought: the New Regional Science and the National Innovation System (NIS) approach (Cooke et al., 1998). Following Cooke et al (1998) and Cooke (2002), the emergence of a regional system of interactions, through which the actors exchange tacit and codified knowledge, depends on: 1) local institutional factors, such as a cooperative culture, association, learning

Departamento de Economía, Universidad Nacional del Sur (UNS), Instituto de Investigaciones Económicas y Sociales del Sur (IIESS), Consejo Nacional de Investigaciones Científicas y Técnicas (CONICET). San Andrés 800, Bahía Blanca (Provincia de Buenos Aires), Argentina. *Corresponding author: carolina.pasciaroni@uns.edu.ar 
predisposition, associative consensus; 2) organisational factors at the firm level (labour relations) and organisational factors of policy and governance (propensity among the policy makers to inclusivity, delegation and networking); 3) it could be added organisational and institutional factors at the level of universities and other kind of knowledge organisations, for example formal and informal rules relating to the transfer of knowledge or the presence of Technology Transfer Offices (TTOs) (Bercovitz \& Feldmann, 2006); 4) external influences such as the policies and instruments of the National Innovation System, the link with other RISs and international organisations (Cooke, 2002).

The present work suggests that the RIS approach provides an appropriate theoretical framework to investigate the contribution of knowledge organisations to regional dynamics of innovation in developing countries. First, universities, R\&D centres, laboratories, S\&T institutes, are prominent in the analytical structure of the RIS. According to Cooke (2002) and Asheim \& Coenen (2005), an RIS can be represented as a system comprised of two subsystems linked by interactive learning processes. On the one hand, a subsystem of knowledge generation and diffusion involving universities, $R \& D$ laboratories and similar knowledge organisations. On the other, a knowledge application and exploitation subsystem comprised by firms and their relation to suppliers, customers, and other businesses.

A second element supporting the use of the RIS approach to study knowledge organisations in regional contexts is related to the different types of RIs identified (Asheim \& Coenen, 2005; Cooke, 2006). Asheim \& Coenen (2005) provide empirical evidence for a differential function of knowledge organisations depending on whether the RIS is based on synthetic knowledge (mature industries) or on analytical knowledge (ICTs, biotechnology, nanotechnology). In the latter case, the knowledge infrastructure not only supports local innovation processes but drives ex-ante the creation of high-technology systems through the development of spin-offs and the attraction of high-technology firms. High-tech RISs may comprise clusters, technopoles, or S\&T parks.

A third analytical advantage of the RIS approach is that it can be applied to the study knowledge organisations in regions with low innovative potential, less $\mathrm{R} \& \mathrm{D}$ intensity, low-tech production structures, and a weak endowment of knowledge organisations and firms (Tödtling \& Trippl, 2005). Studies on high-technology regions in developed countries show a number of common features: the leadership of a university or an $\mathrm{R} \& \mathrm{D}$ centre; the presence of venture capitalists; public policies that promote the R\&D activities in the fields of ICT and biotechnology (Cooke, 2002; O' Shea et al, 2007; Saxenian, 1996; among others). By contrast, in the case of Latin America, the function of universities and regional research centres is limited to the training of qualified human resources; there are few cases of collaboration with companies that have the potential to achieve greater impact on local economy (CEPAL, 2010; Llisterri \& Petrobelli, 2011).

In sum, the study of RISs becomes useful to confirm the presence/ absence of the elements involved in the processes of knowledge generation, production and dissemination in less regions and developed countries, including the behavioural analysis of the agents, the institutional framework and governance mechanisms (Llisterri \& Pietrobelli, 2011). Nevertheless, in Latin America, the concept of RIS is quite pervasive, partly due to the scarcity of statistical data and the lack of representativeness surveys on regional innovation (op. cit.). Before discussing the role of knowledge organisations in the local context under study (Bahia Blanca, Argentina), in the next section we will discuss the characteristics that assume knowledge organisations in the NISs of Argentina.

\section{Knowledge Organisations in the National Innovation System of Argentina.}

According to the data provided in Table 1, cooperation between universities, $R \& D$ centres and firms are not prolific among South American countries. However, Argentina standing out with rates similar to those recorded for Japan and Norway. While this is encouraging, the cooperative initiatives do not involve the generation of new knowledge: the domestic industries do not carry out R\&D activities in collaboration with research organisations (INDEC, 2005). By contrast, the testing of new products and processes, quality control and technical problem-solving are the main objectives for companies establishing links with the national knowledge organisations (Arza, 2012). 
Table 1. Percentage of Manufacturing Firms that Cooperated with Universities (or Other Higher Education Institutions) and the Government or Public Research Institutes.

\begin{tabular}{|c|c|c|c|c|}
\hline \multicolumn{2}{|c|}{ Links between Firms and Knowledge Organisations } & $\%$ Universities & \% Public Research Institutes & \%Total \\
\hline \multirow{4}{*}{ High } & Finland & 33,8 & 24,84 & 58,64 \\
\hline & Norway & 14,33 & 18,12 & 32,45 \\
\hline & Argentina & 14,47 & 16,08 & 30,55 \\
\hline & Japan & 15,71 & 14,38 & 30,08 \\
\hline \multirow{4}{*}{ Medium } & Sweden & 18,27 & 8,81 & 27,08 \\
\hline & Germany & 17,12 & 8,12 & 25,24 \\
\hline & France & 13,23 & 10,77 & 23,99 \\
\hline & Ireland & 13,05 & 10,03 & 23,08 \\
\hline \multirow{6}{*}{ Low } & Spain & 7,26 & 9,71 & 16,98 \\
\hline & Colombia & 11,16 & 5,3 & 16,46 \\
\hline & Brazil & 6,3 & .. &.. \\
\hline & Ecuador & 5,71 & 3,04 & 8,75 \\
\hline & Italy & 5,29 & 2,16 & 7,46 \\
\hline & United Kingdom & 4,73 & 2,52 & 7,25 \\
\hline
\end{tabular}

Source: UNESCO, 2010. Note: Data for Argentina for the year 2007; data for Brazil, Ecuador and Japan for year 2011.

The weak link between firms and knowledge organisations in the NIS of Argentina, and in South America in general, is explained by a number of factors. First, these countries have a low expenditure on R\&D as percentage of gross national product (GDP), combined with a low share of high-technology sectors in manufactured exports. Figure 1 shows the differential position of South America in comparison to developed countries. Still, Argentina, and especially Brazil, achieves a relatively higher position. Secondly, unlike developed countries, in South American countries, R\&D spending financed by the government -through its public universities and R\&D centres- exceeds the expenditure recorded for the private sector (Table 2). In the case of Argentina, the public knowledge organisations concentrate $76.1 \%$ of expenditure on $\mathrm{R} \& \mathrm{D}$. The low share of private companies in national $\mathrm{R} \& \mathrm{D}$ expenditure is consistent with the high percentage of companies investing in machinery and equipment (80.4\%). The high representation of government R\&D spending, along with a few historical cooperative initiatives between public knowledge organisations and firms, derived in the following observation: "outside the firms, there is capacity for research and technological consultancy which could be built upon in order to overcome their innovative disadvantages" (Arocena \& Sutz, 1999)
Figure 1. Percentage of High-Technology Exports and Research and Percentage of Development Expenditure

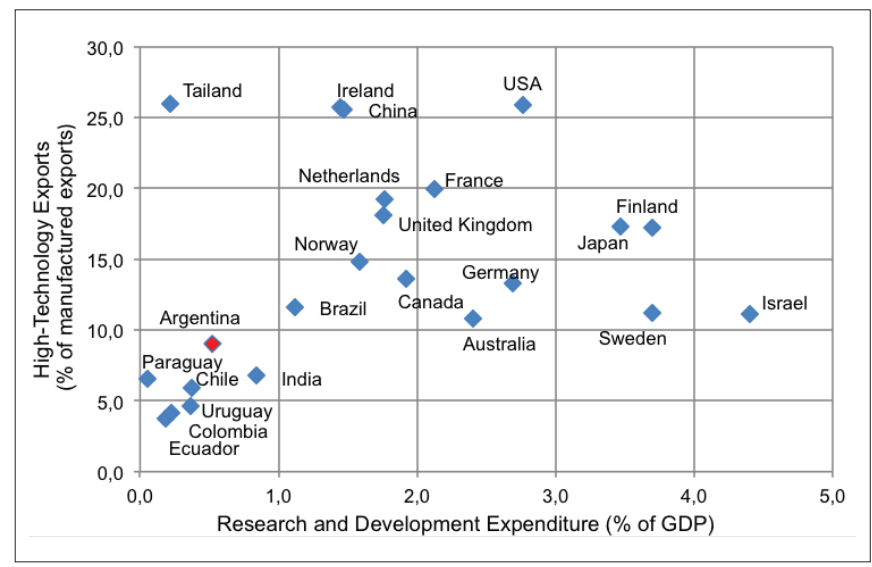

Source: World Bank, 2010. Note: Data for Thailand for the year 2007; Ecuador for 2008; Peru for 2004; Ecuador for 2011. 
Table 2. Percentage of R\&D Financed by Firm, HigherEducation and Government.

Percentage of Manufacturing Firms that Engaged in Acquisition of Machinery, Equipment and Software

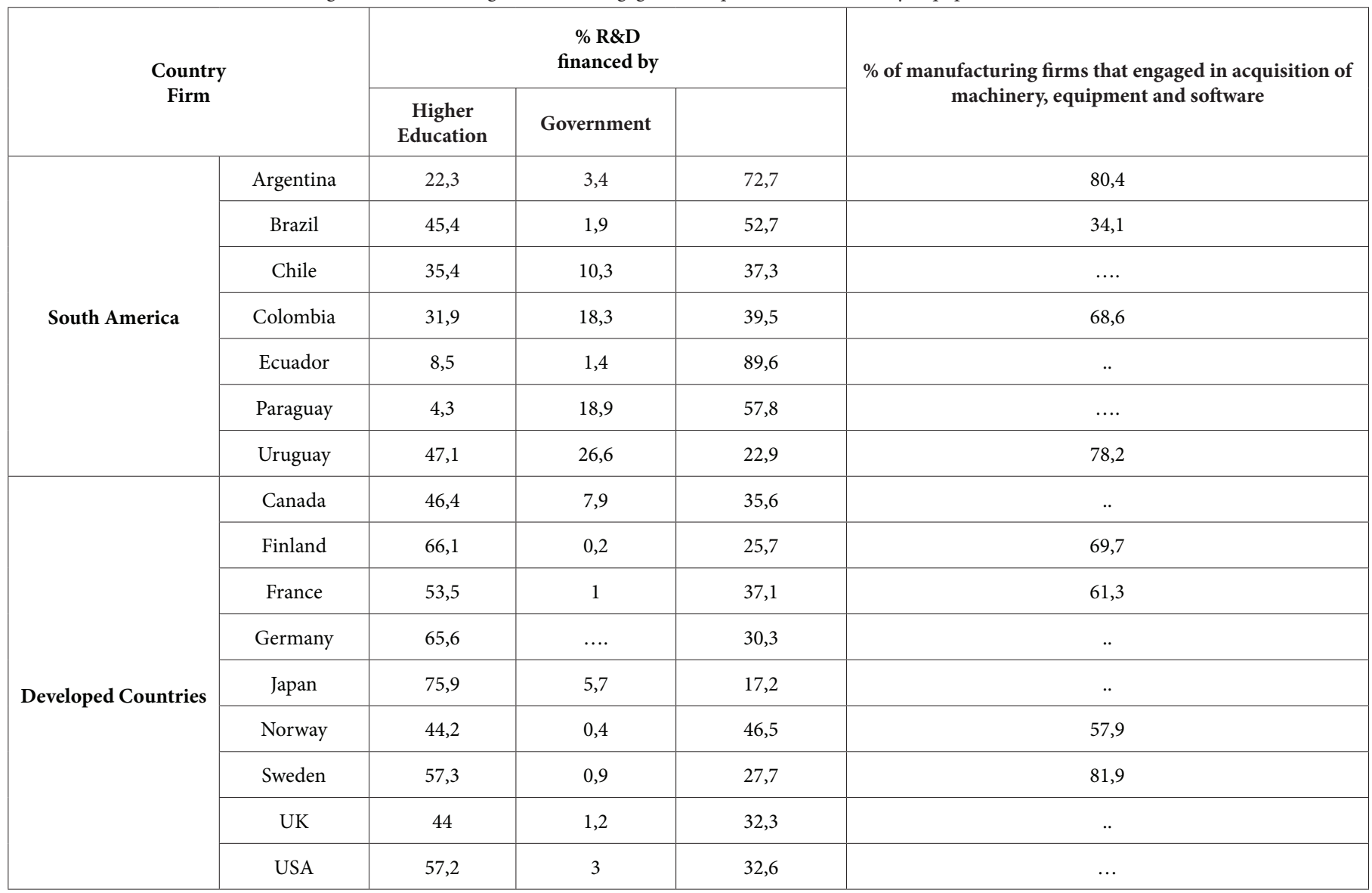

Source: UNESCO, 2010. Note: Data for Ecuador for the year 2008; Paraguay, Japan and Sweden for 2011.

A third factor explaining the few or weak links with the private sector is the founding mission of public knowledge organisations, not oriented to the knowledge diffusion to the productive sector. Following Arza (2012), public universities in Latin America were founded before public R\&D centres, and their mission was oriented exclusively to graduate education. Later, R\&D centres resulted from the development policies that proliferated after the Second World War. Most of these centres were focused on basic and applied research, and a few of them were oriented to assist strategic productive sectors. Argentina experienced a similar historical process. In 1950, the main public S\&T centres were created:

1) the Institute of Agricultural Technology(INTA, acronymin Spanish) and the National Institute of Industrial Technology (INTI, acronym inSpanish) with themission togenerateand transferknowledgeto the agricultural and industrial production sectors, showing a limited success;

2) the National Atomic Energy Commission (CNEA, acronym in Spanish) and the National Research Council (CONICET, acronym in Spanish). The creation of the National Atomic Energy Commission responded to military strategy, but later encouraged the emergence of a group of firms with a high level of technological sophistication (next section). The National Council of Scientific and Technological Research was created within the academic community in order to professionalise scientific activity, following the model of French CNRS. Historically, its operating logic was based on the linear model of innovation, privileging basic research (especially biomedical sciences, physics and chemistry). Its relation with the production system was "not only poor, but rather resisted" (Lopez, 2002, p. 67).

Beyond the common historical process in the development of R\&D centres, Argentina has a number of distinctive features compared to other countries in South America. Excluding Brazil -the only country in the region whose R\&D expenditure exceeds $1 \%$ of GDP- Argentina shows a steady growth of this indicator (Figure 2), recording a growth rate of $45.34 \%$ between 2007 and 2012. This is the result of a new S\&T policy aimed at strengthening the NIS. 
Figure 2. South America. Evolution of Percentage of R\&D Expenditure to GDP



Source: Compiled by the author based on RICYT (Red de Indicadores de Ciencia y Tecnología -Iberoamericana e Interamericana) data.

Following Brazil in chronological order, Argentina is the second country in the region prioritising its S\&T policy through the creation of the Ministry of Science, Technology and Productive Innovation (MINCYT). In general, its S\&T policy adopted a laissez-faire philosophy, with very few exceptions, such as a policy aimed at achieving informatics autonomy in the 80s (Chudnovsky, 1999). In the 90s, in a context where neoliberal macroeconomic policies gained strength, activities of innovation in the private sector were promoted, as well as cooperative initiatives between public knowledge organisations and the productive sector. From the first half of the 2000s, new deviations from the historical laissez-faire tradition are recorded:

1) the Ministry of Science, Technology and Productive Innovation is created in 2007 and related science, technology and productive innovation plans are formulated;

2) links between public knowledge organisations and productive sector are promoted by developing training programs in the field of technology transfer. In addition, new financing modalities are introduced for cooperative projects of innovation involving companies and knowledge organisations;

3) knowledge areas (biotechnology, ICT and nanotechnology) and socio-productive nuclei (agribusiness, environment and sustainable development, social development, energy, industry and health) are promoted because they are considered strategic for economic development. The creation of The Argentinean Nanotechnology Foundation and the introduction of new public financing lines for biotechnology, nanotechnology and renewable energy (FONARSEC Funds) are an example of it;

4) a more equitable distribution of S\&T activities is pursued at regional level.

As this study adopts a regional analysis approach, it should be noted that science, technology and productive innovation policies and programs in Latin America are designed by the national authorities and applied throughout the country (Llisterri \& Petrobielli, 2011).
National authorities also design programs oriented to decentralise policies in science, technology and innovation. However, these programs are designed and implemented in the absence of agreements between different levels of government on priorities and resources needed to carry out such decentralised policies (op. cit.).

\section{Methodology: Case Study Analysis.}

In this work, the case study methodology is applied which is widely used in the RISs approach. As discussed in Section 2, the NIS of Argentina has some specificity that encourages the study of knowledge organisations at regional level. In this scenario, the knowledge organisations of the city of Bahía Blanca are selected as case study. Secondary information from institutional reports was combined with primary information collected through interviews with faculty researchers and local actors. Briefly, Bahía Blanca is a medium-sized urban centre (300.000 inhabitants according to the latest population census) located in the Province of Buenos Aires (main economic and demographic area of the country). The city concentrates a varied public S\&T infrastructure, including the National Southern University (UNS, acronym in Spanish) and its 12 S\&T centres, also dependent on the National Research Council (CONICET, acronym in Spanish). This public university, founded in the mid-50s has shown a marked vocation towards $\mathrm{R} \& \mathrm{D}$ activities.

The choice of the proposed case study was based on the following:

1) Long-standing trajectory in knowledge diffusion to the productive sector. The local knowledge infrastructure has a history of networking dating back to the 70s, starting with the performance of the PLAPIQUI Institute (Chemical Engineering Pilot Plant) as an external laboratory for important firms of the city belonging to the petrochemical industry. This experience was considered an exceptional phenomenon in the NIS (Chudnovsky \& López, 1996). Currently, the knowledge infrastructure of the city provides services and technical consultancy to local and extra-local companies in various productive sectors, especially medium and low knowledge intensity sectors. Conversely, collaborative R\&D projects between companies and local faculty researchers are scarce. 
2) Breakthroughs in the ICT field. As will be discussed below, Bahía Blanca stands out in the national scenario for the promotion of a high-technology innovation system: a S\&T Park in high-complexity electronics. The good performance of this Park would allow counteract the specialisation of the city in productive sectors of medium and low knowledge intensity, such as the petrochemical, food and beverages, furniture manufacturing and commercial activities.

\section{Promoting a Local System of High-Complexity Electronics: Impulses and Limitations.}

This decade, the public knowledge infrastructure of the city of Bahía Blanca experienced its first university spin-off, while it promoted the construction of the first S\&T Park in high-complexity electronics in the country. In Argentina, unlike universities and R\&D centres from developed countries, spin-offs are not a widespread phenomenon among knowledge organisations. They have occurred in a few public universities, like the University of Buenos Aires, the University of Córdoba and the National University of the Littoral, along with National Atomic Energy Commission (see Lugones \& Lugones, 2004). The firms involved fall within the fields of biotechnology and ICT, most of which have developed since the 90s.

In the case of Bahía Blanca, its first spin-off belongs to the field of Electronic Engineering and is the result of collaborator work on an R\&D project between a group of local faculty researchers and the University of Sydney (Australia). This R\&D project originated from a request by a large mining company to the University of Sydney, with the aim of improving work safety on their mines. Thus, the local spin-off began in 2008 and specialised in the development of systems oriented to improve work quality in hostile environments.

Later, the same group of local faculty researchers promoted the construction of an S\&T Park called "Technological Platform for Systems of High-Complexity Electronics Technology" (TEAC, acronym in Spanish). This S\&T Park has high-complexity infrastructure and equipment. Its aim is to encourage the development of high-tech firms and create an innovative environment for the interaction between universities and firms for the holistic production of prototyping complex circuits with macro, micro and nano electronic. Accordingly, the Park aims to offers electronics SMEs: infrastructure equipment, S\&T knowledge, human resources and taxfree imports and exports. The creation of this S\&T Park formally began in 2011 with the efforts of purchasing equipment. Equipment purchases were completed in 2014 and were conducted through public tenders. In late 2012, the building investments were made, and the laboratories were opened in October 2013 (TEAC, 2015).

It should be noted that the electronics industry in Argentina dates back to the $60 \mathrm{~s}$, and since then, it has geographically concentrated in the densely inhabited Buenos Aires (Capital City) and its metropoli$\tan$ area. Therefore, the creation of the aforementioned S\&T Park was not based on a pre-existing large group of electronics firms in the city under study. As Asheim \& Coenen (2005) states, in high-technology RISs, knowledge organisations play a foundational role: promoting the emergence of new industries in the city.

The local S\&T Park in highly complex electronic circuits is particularly relevant when taking into account the fact that circuits are key elements in the value chain of the electronics industry. Moreover, the importance of this S\&T Park can be based on certain features of the domestic electronics industry. With this in mind, a report by the Ministry of Science, Technology and Productive Innovation (MINCYT, 2013) indicates:

- a persistent and increasingly negative trade balance. Briefly, the electronic industry in Argentina consists of about 740 firms and "industrial electronics" is the main segment. The imports focus on communications and data processing;

- around a third of the national market (excluding the assembly industry in Tierra del Fuego) is supplied with printed circuit boards from abroad. These imports are led by national companies that assemble products developed abroad or develop electronic systems

- the domestic electronics industry is currently far from microelectronics. It is necessary to strengthen the offer of services related to the microelectronics industry to meet the requirements of companies without internal capacity to develop integrated circuits. In addition, it becomes relevant to increase the number of human resources in Electronic Engineering, specifically in the management of design tools;

The proposed case study, and its comparison with successful experiences in developed countries, allows identifying factors fostering and limiting the emergence of high-tech systems of innovation in peripheral regions (Table 3). The following factors involved in the local case are presented below: a) high quality of the local academic staff; b) local organisational weakness; c) lack of integration between institutional frameworks at different scales and d) availability of national public funds. 
Table 3. Local Knowledge Organisations and High-Tech RISs

\begin{tabular}{|c|c|c|}
\hline Local Knowledge Organisations & Developed Countries & Case Study \\
\hline Human Resources & Academic excellence & Academic excellence \\
\hline \multirow[b]{2}{*}{ Organisational Factors } & Long-standing active TTOs & Recently created internal TTO \\
\hline & $\begin{array}{l}\text { Strong networks with the industry through collaborative } \\
\qquad \text { R\&D projects }\end{array}$ & $\begin{array}{l}\text { Weak networks with firms in the field of Electronic } \\
\text { Engineering. } \\
\text { Strong academic networks with foreign universities and } \\
\text { S\&T centres. } \\
\text { Internal fragmentation. }\end{array}$ \\
\hline Institutional Factors & $\begin{array}{l}\text { Strong leadership. } \\
\text { Foundational values oriented to the knowledge transfer. } \\
\text { Policies promoting interaction with firms and } \\
\text { entrepreneurship. }\end{array}$ & $\begin{array}{l}\text { Foundational values not oriented to the knowledge } \\
\text { transfer. } \\
\text { Incipient "Institutional reflexivity. } \\
\text { Scarce incentive to networking and entrepreneurship. }\end{array}$ \\
\hline
\end{tabular}

Source: Compiled by the authors based on Asheim and Coenen (2005); Cooke (2002); O'Shea (2007);

Bercovitz and Feldmann (2006); Tödtling and Trippl (2005).

5.1. a. Quality of the Academic Staff. The exceptionally well developed scientific research is one of the main features of high-technology RISs in developed countries (Cooke, 2002). In particular, O'Shea et al. (2007) notes that a key ingredient for successful technology transfer at MIT is its distinguished faculty, the quality of its faculty, and their ability to generate radical innovation conducive to commercialisation.

In the present case, the promotion of a RIS on electronics in based on the pre-existence of a university -The Southern National University-, which offers degrees and postgraduate degrees in Electronic Engineering and has extensive experience in R\&D in this discipline. In the 60 s, the Southern National University and the University of Buenos Aires were the only academic institutions in the country with projects based on the creation of a computer. These projects have positioned Argentina as the only Latin American country with a long track record of knowledge in the area of information technology (Erbes et al, 2006).

Currently, the local knowledge infrastructure integrates the set of national and public centres with research groups and laboratories involved in microelectronics (The Catholic University of Córdoba, the National Institute of Industrial Technology, the National Atomic Energy Commission, the National Technological University, the University of Buenos Aires and the University of San Martín). The local faculty research group stands out nationally for: a) the completion in 2007 of the first doctoral thesis in microelectronics in the country and, b) micro chip designs in 3D technology, in collaboration with foreign universities (The Johns Hopkins University in the USA and the University of Sydney in Australia) and leading international firms in electronic circuits manufacturing.

Within the knowledge infrastructure of Bahía Blanca, the field of Electronic Engineering shows above-average values for its number of trainees and papers per teacher-researcher. Although there is empirical evidence for a negative relationship between the number of papers and academic spin-offs (Landry et al. 2006), the lagging character of the NIS in comparison to countries leading the introduction of technological innovations makes it relevant to consider the number of papers published as an indicator of enough knowledge accumulation to develop technology capable of being commercialised. A distinctive aspect relates to the willingness of this researchers group to carry out their academic activities in collaboration with foreign universities and companies is remarkable. Thus, they link with important companies of integrated circuits, universities and S\&T centres of USA, Australia and Taiwan.

5.2. b. Local Organisational Weakness. Numerous studies analyse Technology Transfer Offices (TTO), its structure and other kinds of internal factors affecting its performance (Bercovitz et al, 2001; Siegel et al, 2003). In the case of more complex mechanisms of technology transfer, such as the creation of spin-off firms, longitudinal analysis on US and Europe universities provide evidence supporting the positive relation between human resources dedicated to knowledge transfer activities and the number of academic spin-offs (Gomez Gras et al, 2008; O 'Shea et al, 2005). In turn, O'Shea et al. (2007) attributes the good performance of MIT (USA) to the early creation of an Office of Technology Licensing (OTL), its active performance in the management of intellectual property; and the search for capital risk to finance start-ups. This type of organisation facilitates the interaction between faculty researchers and venture capitalists, while providing technical, legal and administrative assistance for the establishment of firms.

In the present case, until 2007 the local knowledge infrastructure lacked internal TTOs dedicated to managing and promoting knowledge diffusion. Therefore, the process of spin-offs development took place prior to the creation of this type of offices. It should be noted that, for more than two decades, the local knowledge infrastructure has had 'Technological Network Units' (UVTs, acronym in Spanish), defined as non-state entities, external to knowledge organisations, which have the task of facilitating the dissemination of technology and technical assistance to the productive sector. However, local UVTs did not participate, or did so only marginally, in the development of the spin-off 
and the S\&T Park in high-complexity electronics. In general, these UVTs do not have human resources staff specialised in the development and management of academic spin-offs.

In this scenario, faculty researchers in Electronic Engineering, who promoted the first local spin-off and the creation of the S\&T Park, asked for assistance not only to the UVT but especially to professionals outside this organisation (UNS, 2011). The support was requested 1) for the development of the business plan, the economic evaluation, and the compliance with the legal requirements for the creation of the spin-off, and 2) for the observation of the requirements of the public funding involved in the construction of the local S\&T Park.

On the other hand, in terms of cooperation and organisational proximity (Boschma, 2005), local experience shows a "fragmentation" or a lack of interactions and local networks (Tödtling \& Trippl, 2005), that reveals in the following aspects: 1) the local researchers group do not have a long tradition of knowledge generation and diffusion to the productive sector. By contrast, the gestation of the first local spin-off arises from the academic ties with a foreign university, linked to a large mining company and 2) the creation of the S\&T Park did not involve interaction between the R\&D group under study and the remaining teacher researchers from the career of Electronics Engineering.

\section{3. c. Lack of Integration between National and Local Institutio-} nal Frameworks. In the systemic approach, institutions, comprising rules, regulations, conventions, and routines, condition the emergence and development of learning and innovation processes (Cooke et al, 1998; Lundvall \& Johnson, 1994). Similarly, the literature on academic spin-offs indicates that the formal and informal norms regulating knowledge organisations; their founding mission; their corporate culture are key institutional factors in the development of entrepreneur projects of this kind (Moray \& Clarysse, 2005; Landry et al, 2006; O'Shea et al, 2007). It is important to note that the contribution of universities to regional innovation processes depend on the degree of interaction and mix of the different levels of policies and governance, including the national, regional, local and university level (Charles, 2006). In the case under study, no interactions between these levels of governance and policies are verified.

At national scale, specially, in the complex formed by national universities and research centres of the National Research Council (CONICET, acronym in Spanish), institutional factors do not stimulate interaction between knowledge organisations and firms:

1) some resistance is met in the relation with the productive sector, based on rooted prejudice, ideological and political differences, and with the conception of knowledge as a public good, not as something that can be privately appropriated (Lugones et al, 2006);

2) academic productivity is evaluated by the number and quality of the papers published, disregarding to some extent the relevance of networking activities. This evaluation system operates in detriment of more complex networking activities, especially the creation of academic spin-offs. On the one hand, a spin-off involves a greater time commitment compared to the provision of technology services;
3) there is no specific regulation governing the participation of faculty researchers in firms arising from R\&D projects, or determining whether faculty researchers may own a company, collect royalties and/or profits, or participate in its management, etc.

The specificities of local knowledge organisations can compensate the scarce encouragement towards the creation of networks stemming from the type of evaluation system used and the institutional vacuum (Siegel et al, 2003; Charles, 2006). By contrast, in the case under stu$\mathrm{dy}$, the local institutional environment does not promote interactions between the academic and the productive sectors. This translates into an absence of a "reflexive logic" (Wolfe \& Gertler, 2002) to allow knowledge organisations to foster the creation of new knowledge-intensive production sectors The absence of strategic and planned local policies is revealed in the lack of local university-industry strategies at the level of local government; the recent creation of an internal TTO at the level of local knowledge organisations and the recent formulation of a regulatory framework to mend the institutional vacuum on the participation of faculty researchers in academic spin-offs (UNS, 2011).

Institutional reports on the local S\&T infrastructure indicate that most of the academic departments and annexed S\&T institutes are involved in networking activities. However, these activities “(...) result mainly from the natural predisposition of certain teaching and research sectors, which work cooperatively with the authorities of the departments and institutes in search of scientific-technological networking lines, rather than central planning" (UNS, 2004, p. 69).

Regarding the faculty researchers involved, they decided to create a spin-off and promoted the creation of a high-complexity S\&T Park with the aim of promoting the national electronics industry, increasing the number of students in Electronic Engineering, and spreading the entrepreneurial spirit among academics and students (UNS, 2011). Such initiatives are not trivial if we consider that the tradition of knowledge transfer in universities or S\&T centres favours future researchers' capacity to identify marketing opportunities and get the necessary resources to start up a firm (Rasmussen et al, 2014).

5.4. d. The Impulse of National Public Funding. This manuscript focuses on the early phase of an S\&T Park in a peripheral region. In this regard, two inductors factors or sources (Martin \& Sunley, 2010) arise from the analysis of this process of formation: 1) the deliberate action of local faculty researchers, and 2) the grant of public funding. As noted in Part 3, the national S\&T policy has recently turned to promoting socio-productive nuclei and strategic knowledge areas for economic development. In this new S\&T context, the local faculty researchers were granted the Telecommunications Sector Fund (FS TICs 2010) for the formation of the of the previously mentioned S\&T Park. This kind of funds is given to public-private partnerships to improve competitiveness in the ICT sector. The local beneficiaries include the previously mentioned researchers, the National Institute of Industrial Technology (INTI), public-private entities and ICT firms.

As indicated above, the first laboratories were inaugurated in 2013, and the specialised equipment purchases were completed in 2014 
As the S\&T Park is located in a free zone of import and export taxes, in early 2014 the first efforts were made to achieve an agile mechanism for the entry and exit of inputs and prototypes (TEAC, 2015). Moreover, following the creation of this S\&T Park, a micro and nanoelectronics centre was settled. This centre depends on the National Institute of Industrial Technology (INTI, acronym in Spanish) and specializes in the design and verification of integrated circuits. To date, the local S\&T Park made progress in human resources training, in constituting an alliance with the local government for technological prospective and in setting up projects with high-tech private companies (TEAC, 2015). Given the recent establishment of the Park, these advances seem insufficient to analyse its performance. It should be noted that the experiences with some degree of success in the NIS (see Lugones \& Lugones, 2004) suggest that knowledge supply plays a major role in achieving cooperation with the productive sector. This should be considered by those responsible for the local S\&T Park, taking into account that: a) the high-tech sectors not proliferate in the local and national structure production and 2) the firms usually not rely on knowledge organisations as a source of innovation.

\section{Summary and Conclusions.}

The proposed study gathers evidence about the leading role of knowledge organisations in the shaping of high-technology RISs in developing countries. The case study methodology was applied, based on the public knowledge organisations of the city of Bahía Blanca, Argentina. The selection of this case study responds to: i) the differential characteristics assumed by the NIS of Argentina in comparison to other countries in South America, and ii) the long tradition of knowledge transfer from the knowledge organisations of Bahía Blanca to the local petrochemical industry, coupled with the recent creation of its first academic spin-off -a rare phenomenon in the NIS- and the first and only S\&T Park in high-complexity electronics in the country.

It is still premature to assess the performance of the Park. However, local experience allows us to understand the factors behind the promotion of high-tech developments in peripheral regions. As in high-technology regions of developed countries, the S\&T infrastructure under study was central in the creation of the previously mentioned S\&T Park. This key role is based on a recent national S\&T policy which encourages cooperation between public and private sectors; on the academic excellence achieved by the local S\&T infrastructure in Electronic Engineering; and on the initiative of the researchers involved in the project. However, as opposed to the successful experiences recorded in developed countries, there are production, organisational and institutional obstacles, at national and local levels, hindering the generation and dissemination of knowledge from universities and R\&D centres to the local productive sector.

At a national scale, this work presents empirical evidence to demonstrate that companies and universities in Argentina show stronger interaction than others Latin American countries. While these data are encouraging, the cooperative initiatives are based mainly on assistance and technical services, rather than on more complex knowledge diffusion mechanisms. This weakness of this link responds to a low technology productive structure and institutional factors. The low technology productive structure hinders the emergence of a strong demand for the services offered by the S\&T Park of high-complexity electronics under study. Furthermore, teacher researchers from the NIS organisations have a long tradition of resistance to cooperation due to strongly held prejudice, ideological reasons and the fact that the evaluation of teaching and research activities does not involve an assessment of the knowledge-transfer initiatives.

Locally, aside from the initiative of the R\&D group under study, no organisational or institutional specificities could be identified for the local S\&T infrastructure which could offset the previously mentioned obstacles. In this sense, the local S\&T infrastructure lacks a "reflexive logic" for the creation of active TTOs and the formulation of strategic policies aimed at encouraging interactions with productive sectors, entrepreneurism among students and the faculty, and a higher impact on local economy. Likewise, there is a certain degree of fragmentation and absence of organisational proximity in terms of cooperation with the local S\&T infrastructure.

In sum, the case study falls within the following observation by Arocena \& Sutz (2006): “Innovation clusters are 'cells' within Innovation Systems. In the North, they are numerous and varied; they are wellconnected with each other and with other components of the "system; they are often protected, and they have a long-standing track record. In the South, the picture is different; innovative clusters often have to defend their existence in the interstices of dominant power relations and, more often than not, they succumb."

\section{References}

Anselin, L., Varga, A. \& Acs, ZJ. (2000). Geographical Spillovers and University Research: A Spatial Econometric Perspective. Growth and Change, 31(4), 501-515. http://dx.doi.org/10.1111/0017-4815.00142.

Arocena, R. \& Sutz, J. (2006). El Estudio de la Innovación desde el Sur y las Perspectivas de un Nuevo Desarrollo. Revista Iberoamericana de Ciencia, Tecnología e Innovación, No 7 [online] http://www.oei.es/ revistactsi/numero7/articulo01.htm (Accessed 15 July 2015).

Arocena, R. \& Sutz, J. (1999). Mirando los Sistemas Nacionales de Innovación desde el Sur. [online] http://www.oei.es/salactsi/sutzarcena. htm (Accessed 15 July 2015).

Arza, V. (2012). What Kind Of Development Research Centres Latin America Needs? Research Organisations and Policy Making In Latin America. Paper presented at the Workshop "What Kind Of Development Research Centres Latin America Needs?” Iguazú, Argentina, November 18, 2012.

Asheim, B. \& Coenen, L. (2005). Knowledge Bases and Regional Innovation Systems: Comparing Nordic Clusters. Research Policy, 34(8), 1173-1190. http://dx.doi.org/10.1016/j.respol.2005.03.013.

Bercovitz, J. \& Feldmann, M. (2006). Entrepreneurial Universities and Technology Transfer: A Conceptual Framework for Understanding Knowledge-Based Economic Development. Journal of Technology Transfer, 31(1), 175-188. http://dx.doi.org/10.1007/s10961-005-5029-z. 
Bercovitz, J., Feldman, M., Feller, I. \& Burton, R. (2001). Organizational Structure as a Determinant of Academic Patent and Licensing Behaviour: An Exploratory Study of Duke, Johns Hopkins, and Pennsylvania State Universities. The Journal of Technology Transfer, 26(1-2), 21-35.

Boschma, R. (2005). Proximity and Innovation: A Critical Assessment. Regional Studies, 39(1), 61-74. http://dx.doi.org/10.1080/003 4340052000320887.

CEPAL - Comisión Económica para América Latina y el Caribe (2010). Espacios Iberoamericanos: Vínculos entre Universidades y Empresas para el Desarrollo Tecnológico. Santiago de Chile: Autor.

Cooke, P. (2006). Regional Innovation Systems as Public Goods, Working Papers United Nations Industrial Development Organization, Vienna, Austria.

Cooke, P. (2002). Biotechnology Clusters as Regional, Sectorial Innovation Systems International Regional. Science Review, 25(1), 8-37. http://dx.doi.org/10.1177/016001760202500102.

Cooke, P.; Gomez Uranga, M. \& Etxebarria, G. (1998). Regional Systems of Innovation: An Evolutionary Perspective. Environment and Planning A, 30(9), 1563-1584. http://dx.doi.org/10.1068/a301563.

Charles, D. (2006). Universities as Key Knowledge Infrastructures in Regional Innovation Systems. Innovation: The European Journal of Social Science Research, 19 (1), 117 - 130. http://dx.doi. org/10.1080/13511610600608013.

Chudnovsky, D. (1999). Políticas de Ciencia y Tecnología y el Sistema Nacional de Innovación en la Argentina. Revista CEPAL, № 67, 153-171.

Chudnovsky, D. \& López, A. (1996). Política Tecnológica en la Argentina: ¿Hay algo más que Laissez Faire? Revista REDES, 3 (6), 33-75.

Erbes, A., Robert, V \& Yoguel, G. (2006). El Sendero Evolutivo y Potencialidades del Sector Software en Argentina. In J. Borello, V. Robert \& G. Yoguel (Eds): La Informática en Argentina. Desafíos a la Especialización y Competitividad (pp. 155-170). Buenos Aires: Prometeo Libros.

Etzkowiz, H. (2003). Research Groups As 'Quasi-firms': The Invention of the Entrepreneurial University. Research Policy, 32(1), 109121. http://dx.doi.org/10.1016/s0048-7333(02)00009-4.

Gómez Gras, J.M., Galiana Lapera, D. R., Mira Solves, I., Verdú Jover, A.J. \& Sancho Azuar, J. (2008). An Empirical Approach to the Organisational Determinants of Spin-Off Creation in European Universities. International Entrepreneurship and Management Journal, 4(2), 187198. http://dx.doi.org/10.1007/s11365-007-0061-0.

INDEC - Instituto Nacional de Estadísticas y Censos (2005). Encuesta Nacional sobre Innovación y Conducta Tecnología (ENIT), Buenos Aires, Argentina.
Landry, R., Amara, N. \& Rherrad, I. (2006). Why Are Some University Researchers More Likely to Create Spin-Offs than Others? Evidence from Canadian Universities. Research Policy, 35(10), 1599 1615. http://dx.doi.org/10.1016/j.respol.2006.09.020.

López, A. (2002). Industrialización Sustitutiva de Importaciones y Sistema Nacional de Innovación: un Análisis del Caso Argentino. Revista Redes, 10(19), 43-85.

Lugones, G., Peirano, F. \& Gutti, P. (2006). Potencialidades y Limitaciones de los Procesos de Innovación en Argentina. Working Paper No 26, Centro de Estudios sobre Ciencia, Desarrollo y Educación Superior, Buenos Aires, Argentina.

Lugones, G. \& Lugones, M. (2004). Bariloche y su Grupo de Empresas Intensivas en Conocimiento: Realidades y Perspectivas. Working Paper $N^{\circ} 17$, Centro de Estudios sobre Ciencia, Desarrollo y Educación Superior, Buenos Aires, Argentina.

Lundvall, B. A., \& Johnson, B. (1994). Sistemas Nacionales de Innovación y Aprendizaje Institucional. Comercio Exterior, 44(8), 695-704.

Llisterri, J. \& Pietrobelli, C. (2011). Los Sistemas Regionales de Innovación en América Latina. Washington DC: BID - Banco Interamericano de Desarrollo.

Martin, R. \& Sunley, P. (2010). The Place of Path Dependence in an Evolutionary Perspective on the Economic Landscape. En R. Boschma y R. Martin (Eds.), Hand-book of Evolutionary Economic Geography (pp. 62 - 92). Chichester: Edward Elgar.

MINCYT - Ministerio de Ciencia, Tecnología e Innovación Productiva (2013). Plan Argentina Innovadora 2020. Componentes Electrónicos. Buenos Aires: Ministerio de Ciencia, Tecnología e Innovación Productiva (MINCYT).

Moray, N. \& Clarysse, B. (2005). Institutional Change and Resource Endowments to Science-based Entrepreneurial Firms. Research Policy, 34(7), 1010-1027. http://dx.doi.org/10.1016/j.respol.2005.05.016.

O’ Shea, R.P., Allen. T.J, O'Gorman, C. \& Roche, F. (2007). Delineating the Anatomy of an Entrepreneurial University: The MIT Experience. R\&D Management, 37(1), 1 -16. http://dx.doi.org/10.1111/j.14679310.2007.00454.x.

O'Shea, R. (2007). Determinants and Consequences of University Spin-off Activity: a Conceptual Framework. In F. Thérin (Ed.): Handbook of Research on Techno-Entrepreneurship (pp. 170-183). Cheltenham- Northampton: Edward Elgar Publishing Limited.

O' Shea, R.P., Allen, T. J., Chevalier, A. \& Roche, F. (2005). Entrepreneurial Orientation, Technology Transfer and Spinoff Performance of US Universities. Research Policy, 34(7), 994-1009. http://dx.doi. org/10.1016/j.respol.2005.05.011. 
Rasmussen, E., Mosey, S. \& Wright, M. (2014). The Influence of University Departments on the Evolution of Entrepreneurial Competencies in Spin-Off Ventures. Research Policy, 43(1), 92-106. http:// dx.doi.org/10.1016/j.respol.2013.06.007.

Saxenian, A. (1996). Regional Advantage: Culture and Competition in Silicon Valley and Route 128. Cambridge MA: Harvard University Press.

Scott, A.J. \& Storper, M. (2007). Regions, Globalization, Development. Regional Studies, 41(6\&7), 579-593. http://dx.doi.org/10.1080 /0034340032000108697.

Siegel, D. S., Waldman, D. \& Link, A. (2003). Assessing the Impact of Organizational Practices on the Relative Productivity of University Technology Transfer Offices: An Exploratory Study. Research Policy, 32(1), 27-48. http://dx.doi.org/10.3386/w7256.

TEAC - Tecnópolis del Sur (2015). Informe Preliminar Tecnópolis del Sur. http://www.academia.edu/16325132/Informe_preliminar_ Tecn\%C3\%B3polis_del_Sur. Accessed 28 November 2015.
Tödtling, F. \& Trippl, M. (2005). One Size Fits All?: Towards A Differentiated Regional Innovation Policy Approach. Research Policy, 34(8), 1203-1219.

UNS - Universidad Nacional del Sur (2011). ACTA 657 - Sesión Consejo Superior Universitario de la Universidad Nacional del Sur, 3 de Agosto de 2011, Bahía Blanca, Argentina.

UNS- Universidad Nacional del Sur (2010). Informe de Autoevaluación Institucional de la Función de Investigación y Desarrollo, Bahía Blanca, Argentina.

UNS- Universidad Nacional del Sur (2004). Informe Final Evaluación Externa de La Uni-versidad Nacional del Sur, Bahía Blanca, Argentina.

Wolfe, D. \& Gertler, M. (2002). Innovation and Social Learning: An Introduction. In M. Gertler \& D. Wolfe (Eds.): Innovation and Social Learning: Institutional Adaptation in an Era of Technological Change (pp. 1-24). New York: Palgrave Macmillan. 